\title{
Les Deux Angleterres et le Continent Anglophone Sociology as the Guardian of Old European Semantics ${ }^{1}$
}

\author{
Steffen Roth \\ École Supérieure de Commerce de Rennes, \\ 2 Rue Robert d'Arbrissel, 35000 Rennes, France \\ Hochschule für Wirtschaft \\ Lagerstrasse 15, 8004 Zürich, Switzerland \\ steffen.roth@esc-rennes.fr.
}

\begin{abstract}
"Mark this well, ye proud men of action! Ye are, after all, nothing but unconscious instruments of the men of thought" (Heinrich Heine)
\end{abstract}

\begin{abstract}
Despite its influence in Central European sociology, N. Luhmann's Social Systems theory remains a marginal branch of international sociology. In this paper, the theory questions the reasons for its own marginality in general and for its marginality in the Anglophone centers of sociology in particular, with the latter still being a surprise against the background of the theory's cybernetic roots in the US. The theory arrives at the conclusion that, while Europe, or 'the continent', is still perceived as old compared with the Anglophone new world(s), it still is Anglophone sociology that preserves 'Old European' semantics. Sociology in continental 'Old Europe', however, seems to have a chance of slowly being acquainted with a new, post-enlightenment mindset focused on semantics and communication rather than on humans and action.
\end{abstract}

\footnotetext{
${ }^{1}$ I owe much to the comments and ideas of Isabelle Clerc, Dr. Lukas Scheiber, Martin Kuhn, and Prof. Sandro Cattacin
} 


\section{I - The Periphery of the Center and the Secret Center of the Periphery}

Immediately after the release of 'Die Gesellschaft der Gesellschaft' (Luhmann, 1997), the German key medium DIE ZEIT headlined a 'Farewell of Old Europe' and estimated the book as the opus magnum of one of the most outstanding sociologists of the $20^{\text {th }}$ century (Brunkhorst, 1997). Without any doubt, N. Luhmann's eeuvre had a lasting influence upon the intellectual life of a number of European countries (the Germanspeaking countries, Scandinavia and Italy, in the first instance; cf. Arnoldi, 2001; Seidl and Becker, 2006) as well as the fundamentals of the most diverse disciplines (including philosophy, theology, management studies, political or education sciences, psychology, and, last but not least, sociology), which is why Luhmann is mentioned in the same breath as P. Bourdieu, A. Giddens, M. Foucault, U. Beck and J. Habermas (cf. Outhwaite, 2009: 1034; Seidl and Becker, 2006: 10).

However, even N. Luhmann's most convinced followers ${ }^{2}$ cannot help but assess the only regional influence exerted by his Social Systems theory, which "has largely lost in the competition for chairs, research funds and publishing programs against the cognition sciences, to whose foundation it contributed" (cf. Baecker, 2005: 11). This "lamentably low visibility of Niklas Luhmann's work in the Anglophone world" (Bergthaller and Schinko, 2011:5) is also reflected by the fact that his writings have neither been ranked in the 'ISA top 10 books' (ISA, 1998) ${ }^{4}$ nor in the 'Contemporary Sociology Top 10 Books' (CS, 1996), thus far. Theorists in social systems and their concepts hardly play any role in the contemporary sociological student textbooks (Keith and Ender, 2004; Macionis, 1988; Schrecker, 2008; Wagenaar, 2004). Also in his study on 'Canon Formation in Late $20^{\text {th }}$-Century British Sociology', W. Outhwaite (2009: 1030) lists Z. Baumann, U. Beck, P. Bourdieu and A. Giddens as representatives of the British canon while excluding N. Luhmann, but not without admitting that the in-group is only "proving a loose framework for analysis, rather than laying down formal categories in the manner of Parsons, Luhmann or Richard Münch. Giddens' structuration theory, for example, is contingently rather than logically linked with his substantive analysis of class stratification, state power or globalization" (ibid, p. 1034). Again we find that N. Luhmann's and further system theoretical approaches are perceived as logically strong but as not en vogue in the Anglophone centers of sociology, where theory per se has more than once in history been perceived as "a bad dream from which the discipline has

\footnotetext{
${ }^{2}$ To which H. Willke and D. Baecker are counted among (Turner, 2007).

3 “(D)ie Systemtheorie hat die Konkurrenz um Lehrstühle, Forschungsmittel und Verlagsprogramme gegen die Kognitionswissenschaften, an deren Grundlegung sie mitgearbeitet hatte, weitgehend verloren, aber noch sind ihre Spuren nicht alle getilgt" (Viskovatoff, 1999: 482).

4 'Social Systems' ranks 29th, while in the top 10 we find M. Weber (rank 1), C. W. Mills, R. K. Merton, again Weber, P. L. Berger and T. Luckmann, P. Bourdieu, N. Elias, J. Habermas, T. Parsons, and E. Goffman (rank 10). With a second title on rank 24, Habermas outperforms Luhmann twice.
} 
been awakened by the kiss of science" (Connell, 1997: 1539), i.e. a straightforward sphere of empiricism-driven concepts and decent middle-range theories.

N. Luhmann (1984) obviously is not interested in exhibiting decent behavior in this vein: Already in the subtitle of the German version of his 'Social Systems' he pledges an 'Outline of a General Theory', i.e. a theory that

"(D)oes claim universality for its grasp of its objects in the sense that as a sociological theory it deals with everything social and not sections (as for example strata and mobility, particularities of the modern society and patterns of interaction, etc.). Theories that claim universality are easily recognized by the fact that they appear as their own object. (If they wanted to exclude themselves, they would have to surrender the claim of universality.)" (Luhmann, 1995: : xlvii; cf. also Luhmann, 1984: 9).

However, how could such a universal theory decide whether it works properly? "By expressively admitting other languages (theory projects). It tests its claim to universality by giving up its claim to exclusiveness. It is thus dependent on competing theories. We could call this principle inclusive competition" (Podak and Roberts, 1986: 58). Otherwise stated the question of the theory's significance and standing is of utmost importance not only in the sense of theory politics or marketing, but also concerning its own architecture.

Therefore, Social Systems Theory has to understand the situation it is in. As a theory of the social referring to itself as a merely social phenomenon, the only option it has to achieve this is communication, which is most briefly defined as the opposite of causality (cf. Baecker, 2012). "Communication means to be unsure about cause and effect" (Baecker, 2001: 60). The theory has, therefore, to tell a story for the reasons for its current marginality in the metropolises of sociology (Connell, 1997: 1535); and then wait and see whether and how this story is perceived and how it changes the relation between the theory and its environment. This is what the present paper will discuss.

\section{II - Social Systems Theory: The Heir of Macy}

The current marginality of Social Systems Theory in the relevant Anglophone discourses takes the theory by surprise considering the fact that, at least geographically, one of the major starting points was in the USA (Umpelby and Dent, 1999; Clerc, 2010), i.e. the conferences the Macy Foundation sponsored between 1946 and 1953. In the course of this interdisciplinary series of conferences Circular Causal Feedback Mechanisms in Biological and Social Systems has been discussed before the face of an increasingly interested general public, which soon associated the aim of transferring the Macy concepts into the social and behavioral sciences with the label Cybernetics (Pias, 2004). According to F. Fremont-Smith, Medical Director of the Macy Foundation, it was imperative to create new, circular concepts of causality in order to be able to 


\section{Steffen Roth}

overcome the obstructive disciplinary gaps and to establish meaningful forms of communication between the sciences and the humanities, and thus, to prompt the creation of new knowledge on cybernetics:

"Developments of the last few years in the field of mathematics and engineering with special reference to principles underlying computering machines and target seeking devices, when taken together with advances in the field of neurophysiology, promise to throw light upon the mechanisms underlying selfcorrecting and purposeful behavior of individuals and of groups. This frame of reference should be of interest to those working in the fields of psychology, psychiatry, anthropology and sociology." (Invitation letter from F. Fremont-Smith, 8. Februar 1946, reprinted in Pias, 2004)

While the conference title could lead us to believe that the 'Cybernetics' was primarily concerned with 'purposeful behavior', conference protocols and records draw a different picture. The most outstanding academics of their time (W. McCulloch as chairman, N. Wiener, W. Pitts, G. Bateson, M. Mead, H. von Foerster, R. Carnap, R. Ashby and J. von Neumann; cf. Heims, 1991) discussed the problems and concepts of language, information, communication, coding, and general systems theory. What is striking about the Macy Denkkollektiv is that many of the participants referred to the New European discourses held in the context of the Wiener Kreis or the journal Erkenntnis in the 1920s and 1930s (Fleck, 2006). By this, the Macy conferences represented an imported hub for New European ideas that, in Europe itself, for the most part, did not survive the Fascist Era. This import included epistemological questions on the smallest units of action or information and on the functioning of communication. On following these and similar questions, Cybernetics soon was confronted with the above mentioned claim that an universal theory needs to appear as its own object and therefore already broke with the idea of objectivity or Archimedean points of view that a theory could self-evidently base on (cf. Hegselmann and Geo, 1991). In such way, Macy anticipated many figures of thought nowadays associated today with the Luhmannian Systems Theory, including the idea of seeing social systems as an 'organic' system, capable of self-regulation“" (Jonas, 1953).

Despite the fact that the call for paper was explicitly oriented to social scientists, we notice the absence of representatives of the sociological mainstream of these days. The only two sociologist who, for a short time at least, participated in the conference were P. Lazarsfeld, founding father of modern empirical social research, and the legendary $\mathrm{T}$. Parsons (Arnoldi, 2001: 3), the second major US-American root of Luhmann's Social Systems Theory ${ }^{5}$.

\footnotetext{
5 "Various social scientists, mainly from the United States, made use of the concept of system, in particular since the periodic conferences instated by Grinker and Ruesch in Chicago during the 1950s (see Grinker, 1956). The participants freely used notions such as adaptation, autonomy, boundaries, communication nodes, effectors, energy system, environment, Gestalt, hierarchy, homeostasis, information, levels, processes of interaction and communication, open systems, organization, circularity
} 
The question therefore remains as to why Social Systems Theory cannot come full circle in terms of an adequate reception in the Anglophone sociology.

\title{
III - The nature of Anglophone Sociological Knowledge
}

In the following discussion, the Theory will approach the problem of its own marginality as a game of sides: It will try to get a picture of Anglophone sociology's self-reference as well as its perception of Social Systems Theory.

The first step is the quest for 'The nature of sociological knowledge', which seems to be unknown even to authors of articles of the same name (Zolo, 1986; Vanderstraeten, 2002), who conclude that:

\begin{abstract}
"Sociological knowledge, it would seem, is much more akin to (...) historical science than any that resembles a natural science. The current challenge confronting our discipline is the assurance that the knowledge we produce is publicly relevant and empirically valid, not that it is necessarily scientific in a cumulative sense. The question is whether or not sociology as a discipline is poised and prepared to accept this challenge. As I have argued elsewhere (...), the future of the discipline rests with its strength as a profession, which like economics, law, psychology, education, and medicine, bridges the academic and public realms. The body of knowledge produced by sociology, it seems to me, is like that of law, evolving and changing through the interpretation and reinterpretation of an established social construction, albeit largely an empirical one of our own making. And like law, it would seem that sociology is much more akin to a profession than to a science".
\end{abstract}

In this sense, sociological knowledge results in a modesty that is developed to such extent that the discipline is publically advised to sound its (at least partial) retreat from the claim of being a science. Rather, sociologists should focus on their individual role as professional boundary spanners between academia and the public, with public expectations being the benchmark for sociological quality. Even if the theory might note that there is a certain tone of constructivism resonating in the paragraph cited, the construction of knowledge remains a matter of the individual 'Sociologist as Ombudsman' (ibid, p. 10), as which “(o)ne acts morally in the profession when one pursues work in a precise and concentrated manner with the intent to achieve an approximation of the ideal" (ibid, p. 12), i.e. "the ideal standards of the craft as a form of moral life" (ibid).

Maybe, the present mindset and sense of mission might be perceived as featuring elements of a caricature. Of course, the idea of the scientific nature of sociology still

of processes, rhythms, structures, steady state, stability, stress, threshold, etc., showing clearly the influence of the then developing cybernetics and systems theory. Among the most prominent participants were Deutsch, Parsons, Rapoport (one of the founders of the original Society for General Systems Research), Thompson and Weiss." (Baecker, 2005: 11). 


\section{Steffen Roth}

belongs to the hardcore of sociological knowledge, even at the level of introduction courses $^{4}$ (Keith, 2006: 11). However, as of the 1920s, the constitutive idea of being the 'Practical Sociology of the Metropole' still has a certain relevance in US-American sociology (Persell et al., 2007: 313). A strong focus on the applied, practical and actorbased concepts can also be noted with regard to the British Islands, both in the context of a comparison between French and British student textbooks ${ }^{6}$ (Connell, 1997: 1535) and with regard to the British sociological canon formation (Schrecker, 2008). Thus, a common feature of both traditions is to flaunt a theory-skeptical attitude (Outhwaite, 2009), which, in return, makes these sociologies more open to and, therefore, more dependent on what they perceive to be the everyday languages and the common senses already existent in the subjects and objects of their research. This, Social Systems Theory should bear in mind when being confronted with virtually all of the Old European concepts it aims to free from their role as guiding stars of social theory: humans, individuals, actions, responsibilities, beliefs, morals, values, decisions, et al.

A second way to discover more about the foundations of Anglophone sociology is to shift the focus from its self-concept to the question of what can be learned from its contact with the new speak (Albrow, 1993: 85f; Outhwaite, 2009: 1034; Connell, 1997: 1539) of Luhmannian theory. In other words, the theory tests its Anglophone environment by watching how the environment reacts to the theory's own operations, this being a strategy that not only hopefully, but unavoidably, will change both the theory and its environment, at least as long as the theory is not completely ignored. At least, this is not the case: If actually regarded, then "Luhmann's work is (...) subject to (...) heated theoretical and political debates both within and outside Germany" (Reckwitz, 2002: 257) with the tendency of dividing the respective contributors in supporters and antagonists. While for some authors Luhmann is the sociologist of the 20th century, for others "Luhmann is perhaps, at best, an uninspiring ambassador of the complexity theory for much contemporary sociology; at worst, a distraction that slowed the utilization of the toolkit of complexity thinking within social theory and discouraged wider engagement in the rethinking of the concept of social system" (Arnoldi, 2001: 12).

Between these two extremes, some significant typical reaction patterns to the theory can be identified (Walby, 2007: 457):

\footnotetext{
"The responses to this highly complex, self-contained, and interconnected theoretical product have been several. One can distinguish several different kinds:

1. Rejection of the theory as speculative and unscientific, insufficiently concerned with empirical verification (Viskovatoff, 1999: 482);
}

6 Both introduction courses and textbooks are highly relevant in defining sociology's public image, as for many people they remain the only more intense contact with sociology (François, 1999: 214). 
2. Rejection of it on the grounds that it gives up humanistic, enlightenment, and emancipatory values, which should be maintained (Zolo, 1986; Wagner, 1994; Wagner, 1997) or because it abstracts from individuals to an absurd degree (Habermas, 1985; Miller, 1994);

3. Use of the theory as a 'toolbox, out of which one can take individual concepts and theorems depending on one's immediate goals, without having to worry about the rest of the theory' (Izuzquiza, 1990);

4. Criticism of the theory from the perspective of general system theory, with the argument that what is constitutive of society is not communications but neural networks or some other biological entity (the papers collected in (Schimank, 1991: 579) or making some other modification of the theory from a natural science perspective (Leydesdorff 1996) while following Luhmann's general method of theorizing;

5. Full-fledged embrace, with little or no criticism of Luhmann's fundamental theory (Schmidt, 1987);

6. Seeing the theory as currently the most advanced sociological theory and hence adopting it, while presenting it less 'self-referentially' than Luhmann or his close disciples do, not working wholly within it, and making connections between it and the sociological tradition (Willke, 1992; Baecker, 1988)“.

Within the Anglophone world, N. Luhmann's œuvre predominantly received critiques of types 1 and 2. Interestingly, these represent the less relaxed and curious or just the more normative and ideological forms of critique, which is not what the theory expected as a reaction of a field displaying itself as a sociology based on empiricism and pragmatism, which would rather suggest to adopt an attitude as presented in type 3 or 5 . In not following what it claims to be its guiding stars, Anglophone sociology gambles away its chances on what the following section of the article will discuss.

\section{IV - The Nature of Social Systems Thinking}

Responding to the mentioned question on What should students understand after taking an introduction to sociology, a leading US-American scholar stated, students should learn that " $(\mathrm{t})$ he things we take granted as natural are really socially constructed, e.g. human nature" (Kiss, 1986; Kiss, 1989). Even though human nature isn't nature it stays human nature. At the same time we might assume that

“(A)s far as the politics of ideas is concerned probably the greatest obstacle to Luhmann's approach was its self-characterization as systems theory. The word 'system' could serve to crystallize all the prejudices. (...) Luhmann did not have any good cards in the political battle of ideas, and he was to feel this in the following years. Seminar papers were able to manoeuvre him - simply through the associative elaboration of the modest conceptual repertoire, which I have quoted ${ }^{7}$ - against the wall, at which the theoretical 'defenders of the status quo' had to await their theoretical execution" (Persell et al., 2007: 308).

7 The authors, in plural despite the use of the individual personal pronoun, hence apparently the author and his translator, quoted J. Habermas. 
Even twenty years after the situation described above by K. Podack and D. Roberts, scholars enter reputable journals with playing the same old keyboard of anticonservative associations. Merely to quote an example we refer to the D. Osterberg's (Podak and Roberts, 1986: 55) discussion of Luhmann's General Sociology, in which he devotes at least one-third of the paper on commenting on what he calls the "cynical" and "anti-left-wing tone of Luhmann's writing" (ibid, p. 15) before agreeing with T. Parsons in calling the USSR's "lack of differentiation between the economy and the polity" a "pre-modern trait, making the system less flexible and adaptive than that of the USA" (ibid, p. 19). In this very sense, US-American sociology appears to resembles a moral rather than a scientific adventure.

The Theory therefore argues that critiques of the above-mentioned type 2 are scientifically irrelevant insofar as they refer to moral values (e.g. the emancipation of whomever) rather than to scientific categories. Taking serious a critique like this would mean the same as accepting that sociological truth were a matter of democracy or of divine right.

The second line of attack refers to what is called a disregard of or an overabstraction from concrete humans, individuals or actions. However, in this respect, the theory cannot quite follow, because it addresses all these and many further concepts, namely as communicative events, i.e. as obviously relevant topics of communication; and then asks whether or not any theory did ever more than communicating the relevance of certain topics (behavior, action, folkways, colonialism, or the internet) ${ }^{8}$. In this sense, the theory can then (only) communicate its surprise that communication used to be a topic belonging to the core of sociological concepts discussed in the 1940s but which then has disappeared from the core until the 1990s (Osterberg, 2000)and has obviously been replaced by the concept of '(collective) behavior' (Keith and Ender, 2004: 27; cf. also Wagenaar, 2004). In any case, even an extensive mapping of Anglophone sociology can easily be performed without any reference to the concept of communication as of the 1970s (Keith and Ender, 2004: 27; Williams and MacLean, 2005: 129).

Whether or not there is a connection between the gap this disappearance left behind and the self-assessed loss of the importance of (Anglophone) sociology, the theory can only consider, at this point of time. However, it might be allowed to speculate this has to do with a feeling that "(s)ociology is largely out of evidence" (cf. Moody and Light, 2006) and, thus, experiences grave image problems (ibid, p. 12): For "( $\mathrm{t}$ )here is no theory of the social" (Keith, 2006: 8), sociology is increasingly perceived as a second

\footnotetext{
${ }^{8}$ The only specific claim that the theory makes is that its topic is what makes the topic a topic, which is communication, i.e. the basic unit of society. In other words: like any other the theory, in fact, has a lot to say, not only but also about individuals, humans, actors, interactors, roles-takers, structure-makers, networking gate-keepers and organizational decision-makers.
} 
string psychology "whose terrain is increasingly being taken up by cognitive science researchers. Even such a concept as trust is now in the hands of economists armed with brain scanning technology" (Podak and Roberts, 1986: 56).

Contemporary Social Systems Theory, however, cannot simply surrender and accept to take the role of a marginal theory within an anyway marginal discipline for one reason: It has been "recently remarked that the biggest impact Luhmann made was that he made people feel that sociology was something special" (Turner, 2007: 359). Indeed, an independent subject matter is exactly what sociology needs, at least, unless it is prepared to accept the claim that "(s)ocial theory cannot get very far without making generous use of mentalistic or cognitive concepts. Even the identification of the domain of social theory, particularly its articulation as 'sociology', that is to say a special discipline concerned with the social, typically relies on cognitive concepts" (Arnoldi, 2001: 12). It depends much on whether one accepts this statement as a true description of the working basis of sociology, or rather as an outline of the foundations of only one particular practice of Anglophone, or Old-European respectively, social sciences:

In the first case, there always remains the problem that the social cannot appear but as footprints in the spheres of consciousness or cognition; in other words: if social theory is based on non-social foundations, then just like in the case of black holes in astronomy, social phenomena can only be observed indirectly through their interaction with other matters. If this indirect strategy of unveiling the social by adding or removing these or those of its non-social boundary conditions actually is considered the standard of doing social sciences, then this leaves us with the question of whether "the fashion for sociological approaches which attempt to reduce reliance on mental and cognitive concepts to a minimum (...) inadvertently show that weak notions of cognition and agency produce weak explanations and very limited understandings of the kinds of questions about the social world that social theory hast traditionally attempted to provide" (Turner, 2007: 357).

As a result of his discussion of this traditional approach to the social, S. Turner (2007) draws the conclusion that social scientists should stop with trying and spotting the invisible, and rather start considering the potentials of 'Social Theory as a Cognitive Neuroscience'. For contemporary Social Systems Theory the case would be clear then: If Anglophone social sciences follows this path, then the Anglophone scientific community has no need for social sciences that are independent from cognitive and natural sciences.

In the second case, there is always the just mentioned alternative of defining an independent subject matter for social sciences in general, and sociology in particular, which is a task that also the Anglophone scientific community obviously has been trying to accomplish throughout the past decades. One instructive testimonial of this effort is discussed by S. Oishi, S. Kesebir and B.H. Snyder, who present the modified version of a Table drawn by E.C. Tolman (ibid: 359) that traces the dividing line 
Steffen Roth

between psychology and sociology at the level of the 'Types of Variables Typically Investigated in Sociology and Psychology', (1952):

\begin{tabular}{|c|c|c|}
\hline \multirow[b]{2}{*}{ Discipline } & \multicolumn{2}{|c|}{ Types of Variables } \\
\hline & Independent & Dependent \\
\hline Sociology & $\begin{array}{l}\text { Structures } \\
\text { Institutions } \\
\text { Organizations } \\
\text { Social network } \\
\text { Discourses } \\
\text { Situations } \\
\text { Identities }\end{array}$ & $\begin{array}{l}\text { Individuals' or collective } \\
\text { Actions } \\
\text { Responses } \\
\text { Interpretations } \\
\text { Emergent propertics at } \\
\text { macro level }\end{array}$ \\
\hline Psychology & $\begin{array}{l}\text { Stimulus conditions } \\
\text { Psyhological states } \\
\text { Individual differences }\end{array}$ & $\begin{array}{l}\text { Individuals' } \\
\text { Cog̨nitions } \\
\text { Feelings } \\
\text { Behaviors }\end{array}$ \\
\hline
\end{tabular}

Table 1: The Types of Variables Typically Investigated in Sociology and Psychology (source: Oishi, Kesebir and Snyder 2009, p. 367).

The perplexing aspect about this Table is that it compactly demonstrates that sociology or the social sciences are obviously perceived to be an ancillary science of cognitive sciences: Structures, institutions, organizations, etc., are conceptualized as explanans, whereas the explanandum clearly is individual behavior: actions, responses, and interpretations. In other words, sociology is conceptualized as a particular answer to the questions of what boundary conditions shape individual or collective behavior. Even if sociology were "the scientific study of interactions and relations among human beings" (cf. Table 1; source: Oishi et al., 2009: 367) ${ }^{10}$, then sociology would be the very opposite of the discussion of individual actions, responses or interpretations. And, even if it comes to collective behavior,

\footnotetext{
9 Hereby "mainly referring to the mainstream social psychology that is mostly American in origin" (Oishi et al., 2009: 336)

${ }^{10}$ We still would have to discuss whether or not society is about the interaction of stomachs, intestines or brain cells.
} 


\begin{abstract}
"The unit being sought cannot merely be seen as a kind of 'stapling together of what is different. Putting it that way meant underestimating the complexity of the relationship of ego and alter, and the emerging 'eigen-selectivity' of this social system. Luhmann's critique is especially directed against the work of George H. Mead - notwithstanding Parsons' positive discussion of Mead as a classic author on this topic (...). Symbolic interactionism builds on a contingency acting alter into the ego and see, quite correctly, the process of mediation as the use of symbols. But it treats the problem only on one side of the interaction, assuming that all is the same on the other. It treats, so to speak, only half of the double contingency. It confines itself to ego's actions, reflections, expectations and anticipations" (McIntyre, 2004: 3).
\end{abstract}

In contrast to this idea, for Social Systems Theory (Vanderstraeten, 2002: 85), social systems emerge "through (and only through) the fact that both partners experience double contingency, and that the indeterminability of such an situation for both partners in any activity that then takes place possesses significance for the formation of structures". This, actually, is something completely different from the concept of 'action', "because a constitutive feature of action is that it must be attributable to individuals" (Luhmann, 1995: 108). In this very sense, the goal of the sociological "analysis is to bring out sharply the non-psychic character of social systems. The autonomy of sociology demands that it not be reducible to the psychic. If we understand the psychic as the secularization and 'scientisation' of the subject, then the strategic meaning of Luhmann's critique becomes apparent" (Vanderstraeten, 2002: 85). Finally, we find that social categories cannot be reduced to (the aggregation of) individual behavior, and thus, we need to ask again why social concepts like institutions, networks or organization should only be perceived as an explanans of individual behavior. In this sense, and with regard to the type 1 critique (unscientific theory, insufficient empirical verification et al.), the question also raised is why it is supposed to be more scientific or more empirical to assume that the social is nothing but a boundary condition of individual or collective behavior. And why algebra should be the only form of mathematics or of logics that sociology should be measured against, considering that Social Systems Theory is designed with a strong connection to G. Spencer-Brown's 'Law of Forms' (Podak and Roberts, 1986: 63), and consequently, to a form of mathematics that can treat not only the variables but also the meaning of operands as subject to change? In this very sense, we understand why Luhmann rejects the claim to the exclusive authority of the methodological standards of conventional (natural) sciences (Arnoldi, 2001: 4). Rather, he provides sociology not only with an independent subject matter, but also with a commensurable form of polymathematics or logics. Therefore, again, the empiristic triumph (Zolo, 1986: 116) of Anglophone social sciences is fine, but we really should consider the idea that social sciences demand forms of empiricism and methods that transcend the methods and logics of the natural sciences. Therefore, again, holding the view that the conventional concepts of 
empiricism of the natural sciences were the benchmarks of sociology is, from our point of view, the most Old-European way of doing science.

\section{V - A Farewell from Old-Europe}

The major claim made in this paper is that there is no Old Europe except for the cases of European scholars copying the Anglophone ways of doing science. By saying this, Social Systems Theory does not imply any disregard of the value of the good Old European enlightenment values (Connell, 1997). Rather, it would like to state that these particular values are oriented to guide only particular forms of sciences (or knowledge politics). In other words, values are not an appropriate form of guidance for science, as science cannot rely on whatever the rules of the distinction between good and bad are, but only on the answer to the question of what is true or untrue. Sociology is therefore not about a reflection on good actors and positive actions (Bialasiewicz and Minca, 2005; Baert and Turner, 2004). Rather, amorality can confidently considered a quality feature. Therefore, while there are maybe theories that are more likeable to the Anglophone ways of thinking, still Social Systems Theory has a logical right to argue that critiques of types 1 or 2 in the typology of the reactions on Social Systems Theory (i.e. the accusation of being a morally or empirically dubious theory) are both inappropriate and irrelevant. Rather, what the theory expects from Anglophone social sciences is a return to their own values of pragmatism and empiricism and, therefore, a closer and unbiased look at the theories ... just because a pragmatic and empirical approach would suggest to interact with a new theory in terms of a type 3 or 6 scenario (i.e. selectively using the theory as a new tool-kit and, maybe, using it in a way that sounds a little less like 'new-speak').

What the Systems Theory learns from this excursion is that its problem is not the somehow naïve Anglophone mainstream of sociology or social sciences, but rather misinterpreted or naïve ideas of Systems Theory, including concepts stating that systems can be of a mixed nature, thus comprehending physical, psychological and social elements at the same time, just as presented by A. Pickel (Vanderstraeten, 2002; Podak and Roberts, 1986; Viskovatoff, 1999). Of course, such systems can be observed just like the actants in the actor-network theory (2007), however, the question still remained whether these obviously non-autopoietic systems provide an adequate level of analysis for sociological theories.

For Anglophone social sciences, the case is as simple as it is to accept that society is not made of humans. The hero of sociology simply is neither man nor human. The hero of sociology is not even an actor anymore. The hero of $21^{\text {st }}$ century sociology is communication. In this sense, we are living in post-heroic times. This, of course, is hard to accept: 
"To an astonishing degree and more than all other, American sociology has positioned itself to a stand up for the Good and to accept the Bad, as best, as a form of 'deviance' that should be the target of social reform efforts. It perfectly copies the classic story of American movies: the Good has a terrible time, it almost fails against its adversaries; but in the end it triumphs against all odds, drives off in a shiny new car and gets a well earned kiss" (Law, 1992; Latour, 1987; Callon, 1995).

All this involves an actor, which sociology as the science of the trans-individual, should quickly dispose, just because the price for remaining with the actor is already set: Social Theory as Cognitive Neuroscience (Turner, 2007), i.e. a situation that no sociologist can genuinely be in favor of. The alternative, of course, involves a narcissistic shock for man. However, well placed in the environment of social systems, man is much freer than he ever could be as the atom of society. By focusing on humans instead of communication, ironically it is, of all, those who make man the measure of all things who actually jail him in their moral, Old-European and well-meaning expectations. But, all too often, well meant is just the opposite of well done. Or rather: well communicated

\section{References}

Albrow M. (1993) 'The Changing British Role in European Sociology', 81-97 in: Nedelmann B and Sztompka P (eds) Sociology in Europe. New York: Walter de Gruyter.

Arnoldi J. (2001) 'Niklas Luhmann: An Introduction', Theory, Culture \& Society 18(1): $1-13$.

Baecker D. (1988) Information und Risiko in der Marktwirtschaft. Frankfurt am Main: Suhrkamp.

Baecker D. (2001) 'Why Systems', Theory, Culture \& Society 18(1): 59-74.

Baecker D. (2005) 'Einleitung', in: Baecker D (ed) Schlüsselwerke der Systemtheorie. Wiesbaden: VS Verlag.

Baecker D. (2012) 'Die Texte der Systemtheorie', in: Ochs M and Schweitzer J (eds) Handbuch Forschung für Systemiker. Göttingen: Vandenhoeck and Ruprecht.

Baert P and Turner B. (2004) 'New Pragmatism and Old Europe: Introduction to the Debate between Pragmatist Philosophy and European Social and Political Theory', European Journal of Social Theory 7(3): 267-274.

Bergthaller H and Schinko C. (2011) 'Introduction: From National Cultures to the Semantics of Modern Society', 5-34 in: Bergthaller H and Schinko C (eds) Addressing Modernity. Social Systems Theory and U.S. Cultures. Amsterdam and New York: Edition Rodopi. 
Steffen Roth

Bialasiewicz L and Minca C. (2005) 'Old Europe, new Europe: for a geopolitics of translation', Area 37(4): 365-372.

Brunkhorst H. (1997) Abschied von Alteuropa. Die Gefährdung der Moderne und der Gleichmut des Betrachters - Niklas Luhmanns monumentale Studie über die 'Gesellschaft der Gesellschaft'. DIE ZEIT. 50.

Callon M. (1995) 'Four Models for the Dynamics of Science.', 29-63 in: Jasanoff S, Markle GE, Petersen JC, et al. (eds) Handbook of Science and Technology Studies. Thousand Oaks: Sage.

Clerc I. (2010) Am Quellcode des Verhaltens. Heidelberg: Carl Auer Verlag.

Connell RW. (1997) 'Why Is Classical Theory Classical?', The American Journal of Sociology 102(6): 1511-1557.

CS CS. (1996) 'Ten Most Influential Books of the Past 25 Years', Contemporary Sociology 25(3): 293-325.

Fleck L. (2006) Entstehung und Entwicklung einer wissenschaftlichen Tatsache: Einführung in die Lehre vom Denkstil und Denkkollektiv. Frankfurt am Main: Suhrkamp.

François C. (1999) 'Systemics and Cybernetics in a Historical Perspective', Systems Research and Behavioral Science 16(203-219.

Habermas J. (1985) Der philosophische Diskurs der Moderne. Frankfurt am Main: Suhrkamp.

Hegselmann R and Geo S. (1991) 'Zur Geschichte der 'Erkenntnis", Erkenntnis 35(461471.

Heims SJ. (1991) The Cybernetics Group. Cambridge, MA: MIT Press.

ISA ISA. (1998) Books of the Century. ISA website, http://www.isasociology.org/books/vt/bkv_000.htm. Accessed at 10 April 2010.

Izuzquiza I. (1990) La sociedad sin hombres: Niklas Luhmann o la teorio como escandalo. Barcelona: Anthropos.

Jonas H. (1953) 'A Critique of Cybernetics', Social Research 20(1): 172-192.

Keith B. (2006) 'The nature of sociological knowledge', The American Sociologist 37(2): 6-14.

Keith B and Ender MG. (2004) 'The Sociological Core: Conceptual Patterns and Idiosyncrasies in the Structure and Content of Introductory Sociology Textbooks, 1940-2000', Teaching Sociology 32(1): 19-36.

Kiss G. (1986) Grundzüge und Entwicklung der Luhmannschen Systemtheorie. Stuttgart: Enke.

Kiss G. (1989) Evolution soziologischer Grundbegriffe: Zum Wandel ihrer Semantik. Stuttgart: Enke.

Latour B. (1987) Science in Action. How to follow scientists and engineers through society. Cambridge (MA): Havard University Press. 
Law J. (1992) 'Notes on the Theory of Actor-Network: Ordering, Strategy, and Heterogeneity', Systems Practice 5(379-393.

Luhmann N. (1984) Soziale Systeme. Frankfurt/M.

Luhmann N. (1995) Social Systems. Stanford: Standford University Press.

Luhmann N. (1997) Die Gesellschaft der Gesellschaft. Band 1 und 2. Frankfurt am Main: Suhrkamp.

Macionis JJ. (1988) 'Textbooks and Sociology: A Case of Professional Dependency?', Teaching Sociology 16(4): 420-423.

McIntyre LJ. (2004) The practical skeptic: Core concepts in sociology. Boston: McGraw-Hill.

Miller M. (1994) 'Intersystemic discourse and co-oriented dissent: A critique of Luhmann's concept of ecological communication', Theory, Culture \& Society 11(101-121.

Moody J and Light R. (2006) 'A View from Above: The Evolving Sociological Landscape', The American Sociologist 37(2): 67-86.

Oishi S, Kesebir S and Snyder BH. (2009) 'Sociology: A Lost Connection in Social Psychology', Personality and Social Psychology Review 13(4): 334-353.

Osterberg D. (2000) 'Luhmann's General Sociology', Acta Sociologica 43(1): 15-25.

Outhwaite W. (2009) 'Canon Formation in Late 20th-Century British Sociology', Sociology 43(6): 1029-1045.

Persell CH, Pfeiffer KM and Syed A. (2007) 'What Should Students Understand after Taking Introduction to Sociology?', Teaching Sociology 35(4): 300-314.

Pias C. (2004) Cybernetics - Kybernetik I. The Macy Conferences 1946-1953. Zürich: Diaphanes.

Pickel A. (2007) 'Rethinking Systems Theory: A Programmatic Introduction', Philosophy of the Social Sciences 37(4): 391-407.

Podak K and Roberts D. (1986) 'Without Subject, Without Reason: Reflections on Niklas Luhmann's Social Systems', Thesis Eleven 13(1): 54-66.

Reckwitz A. (2002) 'Toward a Theory of Social Practices: A Development in Culturalist Theorizing', European Journal of Social Theory 5(2): 243-263.

Schimank U. (1991) 'Review of Niklas Luhmann, Die Wissenschaft der Gesellschaft', Kölner Zeitschrift fuer Soziologie und Sozialpsychologie 43(575-579.

Schmidt SJ. (1987) Der Diskurs des Radikalen Konstruktivismus. Frankfurt am Main: Suhrkamp.

Schrecker C. (2008) 'Textbooks and Sociology: A Franco--British Comparison', Current Sociology 56(2): 201-219.

Seidl D and Becker KH. (2006) 'Organizations as Distinction Generating and Processing Systems: Niklas Luhmann's Contribution to Organization Studies', Organization 13(1): 9-35. 
Steffen Roth

Tolman EC. (1952) 'A theoretical analysis of the relations between sociology and psychology', Journal of Abnormal and Social Psychology 47(291-298.

Turner S. (2007) 'Social Theory as a Cognitive Neuroscience', European Journal of Social Theory 10(3): 357-374.

Umpelby SA and Dent EB. (1999) 'The Origins and Purposes of Several Traditions in Systems Theory and Cybernetics', Cybernetics and Systems 30(79-103.

Vanderstraeten R. (2002) 'Parsons, Luhmann and the Theorem of Double Contingency', Journal of Classical Sociology 2(1): 77-92.

Viskovatoff A. (1999) 'Foundations of Niklas Luhmann's Theory of Social Systems', Philosophy of the Social Sciences 29(4): 481-516.

Wagenaar TC. (2004) 'Is There a Core in Sociology? Results from a Survey', Teaching Sociology 32(1): 1-18.

Wagner G. (1994) 'Am Ende der systemtheoretischen Soziologie: Niklas Luhmann und die Dialektik', Zeitschrift für Soziologie 1994(275-291).

Wagner G. (1997) 'The end of Luhmann's social systems theory', Philosophy of the Social Sciences 27(387-409.

Walby S. (2007) 'Complexity Theory, Systems Theory, and Multiple Intersecting Social Inequalities', Philosophy of the Social Sciences 37(4): 449-470.

Williams JE and MacLean VM. (2005) 'Studying Ourselves: Sociology Discipline Building in the United States', The American Sociologist 36(1): 111-133.

Willke H. (1992) Ironie des Staates: Grundlinien einer Staatstheorie polyzentrischer Gesellschaft. Frankfurt am Main: Suhrkamp.

Zolo D. (1986) 'Function, Meaning, Complexity: The Epistemological Premisses of Niklas Luhmann's 'Sociological Enlightenment", Philosophy of the Social Sciences 16(1): 115-127. 